Article

\title{
Community Cultural Resources as Sustainable Development Enablers: A Case Study on Bukjeong Village in Korea compared with Naoshima Island in Japan ${ }^{\dagger}$
}

\author{
Hokyung Chung ${ }^{1}$ and Jongoh Lee ${ }^{2, *}$ \\ 1 Graduate School of Humanities, Hankuk University of Foreign Studies, 107, Imun-ro, Dongdaemun-gu, \\ Seoul 02450, Korea; sonicbath@gmail.com \\ 2 Department of Global Culture and Contents, Hankuk University of Foreign Studies, 107, Imun-ro, \\ Dongdaemun-gu, Seoul 02450, Korea \\ * Correspondence: santon@hufs.ac.kr; Tel.: +82-10-3368-3760 \\ + The research material has been utilized in a preliminary study, and some preliminary results have been \\ presented at the '2nd Eurasian Conference on Educational Innovation 2019', Singapore, 26-30 January 2019.
}

Received: 15 January 2019; Accepted: 28 February 2019; Published: 6 March 2019

check for updates

\begin{abstract}
With the process of urbanization and post-industrialization, the diversity of regions and their unique cultures have become cultural properties for the competitiveness of cities. The concept of cultural heritage and resources has expanded in recent years. In the past, they were confined to architectural and artistic artifacts, but now, cultural heritage and resources have evolved to include environmental elements, industrial and vernacular construction, urban and rural settlements, and intangible elements related to community activities and ways of life. The community is the carrier of cultural resources and heritage. Cultural heritage sites contribute to the creation of a community's identity. This multi-layered discussion of community engagements in cultural heritages and resources provides a unique approach to understanding cultural properties as sustainability enablers. This paper intends to go beyond the theoretical assumptions of the role of community cultural resources by studying the target research group, Bukjeong village in Seoul, Korea. The paper focuses on the possibilities of community engagement for sustainable development for urban regeneration. It proposes that cultural sustainability in its broader definition should be derived from the community realities of a particular place or cultural context. This approach must be grounded in the principles of regional networks, urban governance, and community-based activities.
\end{abstract}

Keywords: community engagements; cultural property development; sustainable development; cultural resilience

\section{Introduction}

As globalization progresses and post-industrialization has accelerated, the role of regions in sustainable development has increased and the diversity of local culture has become an important factor of urban sustainability. Understanding this change requires paying attention to the historical and cultural resources of a region and its unique community engagements, as well as the community's cultural resilience for sustainable development. Regarding cultural heritage being defined as local identity, the development of community-based cultural resources related to the lives of inhabitants strengthens the region's cultural characteristics.

In Korea, discussions about community-based cultural resources as sustainable enablers have started recently. As local development has mainly focused on physical revitalization, local history 
and community culture have declined, and this development has also led to the degradation of regional characteristics, unique places, and even communities. In this regard, the discussion of cultural regeneration for the protection of both local residents and their quality of life has been persuasive for sustainable development.

Among the UNESCO World Cultural Heritage sites, castle-related legacies are recorded as citadels, castles, walls, fortresses, fortified cities, and townships. There are several castle heritage sites surrounding cities in the world, but it is extremely unusual that castle heritage sites surrounding a modern city like Seoul remain to the present. The castle boundary of old Seoul, the Hanyang City Wall that still remains, is the largest of the existing castles in the world, and Hanyang has been the capital since the late 14th century [1]. The Hanyang City Wall in present Seoul is a cultural resource as well as a socio-historical indicator of Seoul.

Since Seoul was designated as a capital city in 1394, it has become a city with a long history. The Hanyang City Wall, a typical old city relic, is a historical and cultural asset that is contiguous with 9 districts and 22 villages surrounding the inner city center of Seoul and is also a city asset, representing the modernized urban culture of Korea.

Since the efforts to register the Hanyang City Wall as a UNESCO World Heritage Site began in 2013, the old castle remains of Hanyang and its surrounding castle towns have attracted attention as a unique cultural resource of Seoul. This area is mixed with residential space adjacent to the cultural heritage, and Hanyang City is also a place where the wall is integrated with the living area of the residents. In terms of the authenticity of the heritage, the protection and comprehensive management measures of natural resources have become essential for sustainable development.

The Hanyang City Wall has been conserved and partly reconstructed from the castle wall, completed in 1396, of the old city, the capital city of the Joseon Dynasty. It was a boundary of the city and operated like a fence that protected the people living within the wall. However, the intended function of the old city wall disappeared in the process of modernization. The wall has been revived in recent years through excavation and restoration, and is regarded as symbol of the new era seeking harmony between nature and humans for sustainable development. In addition, the community of residents living near the wall boundaries is also considered an integrated living heritage of the new age [2].

The castle town adjacent to the city wall has been overshadowed by the rapid urbanization and expansion of Seoul. It has been recognized as a place to be removed for the preservation and management of the Hanyang City Wall and for improving the urban environment. As social and cultural reflection on the value of the unique local culture has progressed, a new evaluation of the castle town, which contains the urban culture of Seoul from the past to the present, has gradually been discussed. It is well known that the preservation of cultural heritage encompasses not only architectural objects with physical reality but also the varied cultural elements of the region [3] (p. 15).

The castle town is a complicated place where the past and the present of metropolitan Seoul are mixed, and it has a unique history and locality, including community history, culture, and natural resources. Moreover, the community in the castle town itself has the same intangible value as a living heritage. Community activities of the castle town, that are the most distinctive, were formed slowly, unlike the rapid changes of urban circumstances. However, the cultural and social interactions of communities continue, and they have now become the barometer of important urban heritage features.

There is also a need to discuss the cultural properties of the community, which are integrated with the Hanyang City Wall, and its contribution as a sustainable development enabler. Discussions on community engagements in old heritage sites that consider residents and their quality of life are continuously being reviewed and developed.

Based on the assumption that the local community is an important asset for the sustainable development of an area, this study begins with the following awareness of the problem: First, the community's cultural properties can be positioned as a subject of sustainable development. Second, heritage-based community activities creatively and subjectively develop and sustain local assets 
to achieve sustainable development. Third, community engagements with cultural properties can improve the quality of life and happiness of its members and become the basis of elasticity for resolving problems in the region.

\section{Research Framework}

\subsection{Cultural Approach for Sustainable Development}

Sustainable development has become an important topic defining the global challenges of heavy deterioration of the human environment and natural resources. This concept began with a reflection on traditional development, which exclusively focused on economic growth. The development of the concept was a result of more theoretical discussions at international conferences as the awareness of the risks to nature and the collapse of environmental systems increased since the 1970s [4].

The notion of sustainability was provided by the Brundtland Report, which defined this notion as "development that meets the needs of the present without compromising the ability of future generations to meet their own needs" [5] (p. 16). This created some possibilities of connecting environmental consideration to regional developments. Moreover, it provided motivation for subsequent international agreements and gave a basis for sharing economic, social, and environmental awareness regarding development [6]. Some operational means for sustainable development were discussed during the Rio Earth Summit in 1992, and the resulting regional agenda 21 allowed sustainability to be viewed at the regional development level [6-8].

Regarding regions under rapid urbanization, the conference report of the UN-Habitat series, The State of the World's Cities, focused on the cultural impact of globalized tendencies on the matter [9]. This report was concerned with the implications of emerging urban cultural problems under globalization. The idea that culture can be used for sustainable development, i.e., the culture-driven approach, has gradually evolved in areas where unique local cultures remain in cities.

The most notable non-profit network that emerged at the level of implementation of the Habitat Agenda is the global network Best Practice and Local Leadership Programme, established in 1997 [10]. This action has led to an important shift in sustainable development from a theoretical perspective to an implementation one, and from the policy level to the human innovation practice level. The objective of this network is to:

... raise awareness of decision-makers on critical social, economic and environmental issues ( ... ) by identifying, disseminating and applying lessons learned from Best Practices to ongoing training, leadership and policy development activities. Best Practices are actions that have made a lasting contribution to improving the quality of life and the sustainability of our cities and communities. [11]

The recent Habitat conference in 2016 presented a global vision shared for sustainability, equity achievement, and human residential environments [12]. The role of culture in sustainable development began to be discussed in the 2030 agenda.

In September 2015, the 2030 agenda for sustainable development has been defined by the 193 UN member countries. The main action plan of the agenda seeks "for people, planet and prosperity" and it aims to take transformation measures for a resilient and sustainable future world. There are 17 Sustainable Development Goals for a total of 169 targets as the core of the 2030 agenda. In particular, the 11th of the 17 Sustainable Development Goals was briefly mentioned. From this discussion, we can derive a direction for a cultural approach to sustainable regional development [13].

Cultural heritage is particularly mentioned in target 11.4: to strengthen efforts to protect and safeguard the world's cultural and natural heritage. Regarding this cultural approach at the international level to sustainable development, researcher F. Nocca indicated some disadvantages to this problem: 
It is a weak reference because it is not specific on cultural heritage, but it is mentioned together with natural one; furthermore, this specific target deals only with the protection and safeguard of cultural heritage, without any reference to its regeneration. [4] (p. 1885)

The 2030 agenda discusses the role of cultural heritage and resources in sustainable development, mostly focusing on tangible cultural heritage. There is a need to consider the intangible aspects of culture in sustainable development, which is reason enough to consider the living heritage aspects of a culture that changes in the environment and is changed by human activity.

Moreover, culture can perform the role of mediating and articulating the needs and activities of the community through its unique wide extension and applicability, and it ultimately contributes to improving the quality of human life. Cultural properties and programs positively contribute to the sustainable development of economically and physically degraded areas and neighborhoods [14].

Recently, rapid urbanization has been taking place worldwide. As regional and environmental contexts are changing, the concept of cultural heritage is also expanding. In other words, cultural heritage, which was previously confined to architectural and artistic masterpieces, has expanded to include landscapes, industrial and vernacular constructions, urban and rural settlements, and intangible cultural resources including skills and ways of life.

The consideration of the cultural approach to sustainability in the urbanization process continues to expand, but this comprehensive cultural concept is still overlooked in the context of the preservation of cultural heritage or the restoration of historical heritage [15]. Furthermore, as the importance of the living dimension in cultural heritage sites is gradually increasing, community characteristics are being considered as factors for sustainable development in regions with strong cultural specificity.

\subsection{Community Properties for Urban Regeneration}

Since the UNESCO Hague Convention for the Protection of Cultural Property in the Event of Armed Conflict, cultural property has been considered a human heritage on an international level. Although the cultural property discussed in this convention was stipulated in the limited context of protection from war or violence, the convention preamble addressed the human dimension of heritage [16]. Due to this convention, the link between culture and the intangible values of human activities was recognized for the very first time.

In the 1990s, cultural property was directly or indirectly related to the lives of the communities living in the context of cultural heritage. The World Heritage Convention in 1972 presented a direct reference to the communities which live at heritage sites:

... each State Party to this Convention shall endeavor ( ... ) to adopt a general policy which aims to give the cultural and natural heritage a function in the life of the community and to integrate the protection of that heritage into comprehensive planning programmes. [17]

J. Poulios, who has conducted community studies on heritage sites, has focused on the term 'living' which first appeared in the mid-1990s before which there was no reference to any living traditions in the World Heritage Convention and the Operational Guidelines. He stated that the emergence of the concept of 'living' led to a new approach to cultural heritage sites which is different from the physical and material approach to intangible values of cultural resources [18]. As urbanization is accelerating, communities in cultural heritage areas are undergoing changes. Cooperative activities by communities, individuals, and groups based on common interests and values improve the quality of urban life in heritage areas, and in this process, the community becomes a major mediator.

The globalization and restructuring of the economy have increased the economic, social, and physical problems faced by many regions, and there is thus more consideration of various factors that affect communities' well-being and local activities [19]. G. Evans reviewed three models of culture's contribution to urban regeneration. He identified three models through which cultural activity is incorporated (or incorporates itself) into the regeneration process. The three models are as follows [20] (p. 5): 
- Culture-Led Regeneration: Cultural activity is seen as the catalyst and engine of regeneration. The activity is likely to have a high-public profile and frequently to be cited as the sign of regeneration. The activity might be the design and construction (or re-use) of a building or buildings for public or business use (e.g., Tate Modern); the reclamation of open space (e.g., the garden festivals of the 1980s and 90s in Gateshead, Liverpool, etc.); or the introduction of a program of activity which is then used to rebrand a place.

- Cultural Regeneration: Cultural activity is fully integrated into an area strategy alongside other activities in the environmental, social, and economic sphere. Examples include Birmingham's Renaissance where the arts were incorporated with policy, planning and resourcing through the city council's joint Arts, Employment and Economic Development Committee, and in the 'exemplar' cultural city, Barcelona. This model is closely allied to the 'cultural planning' approach to cultural policy and city regeneration.

- Culture and Regeneration: Cultural activity is not fully integrated at the strategic development or master planning stage. The intervention is often small-scale: a public art program for a business park, once the buildings have been designed; a heritage interpretation or local history museum tucked away in the corner of a reclaimed industrial site. In some cases, where no planned provision has been made, residents and cultural organizations may respond to the vacuum and make their own interventions-lobbying for a library, commissioning artists to make signs or street furniture, recording the history of their area, setting up a regular music night, etc. Although introduced at a later stage, cultural interventions can make an impact on the regeneration process, enhancing the facilities and services that were initially planned.

Evans focuses on the role of culture as a major element for regeneration and categorizes its characteristics and use of culture as an element of regional revitalization through various urban cases. This classification presents a theoretical outline based on field studies of culture and regional regeneration and also provides a good theoretical basis for analyzing the characteristics of the field study areas covered in this paper. For example, the case of Naoshima in Japan, which has utilized the arts to achieve regional revitalization, is characterized as cultural-led regeneration. On the other hand, in the case of Bukjeong village in Korea, based on community activities, there are many characteristics of cultural regeneration and elements of culture and regeneration included in complicated informal ways. In order for the community to contribute to cultural activities for urban regeneration, the community's cultural and social initiatives are utilized. Moreover, community members and organizations need to develop their capacities and properties in this way [19] (p. 118):

- Skills: project planning, budgeting and fund-raising, management, organization, development, networking

- Knowledge: of the programs and institutions of regeneration, their systems, priorities, key personnel

- Resources: essential components that local communities need to be able to get things done

- Power and influence: the ability to exert influence over the plans, priorities, and actions of key local and national agencies

This set of components comprises not so much specific principles as a checklist for the particular development strategy can judge how to assess the extent to which it can be regarded as culturally sustainable. Interpreting the components as a possible application in this way offers some approaches for researching the community cultural properties. Moreover, the components comprise tangible and intangible community resources. In converting the propositions based on these components into field research, we come upon categories such as historical cultural context, community cultural properties, and engagements.

The term community is defined as a group of people who work and live in a designated area where regeneration programs are applied. Although there is debate regarding the exact definition of community, there is consensus that a successful community has a sense of belonging and partnership 
among its people [21]. Communities can support a variety of activities that benefit local residents based on their sense of togetherness and socio-cultural identity. A well-formed community improves the quality of life of the local people and develops their pride in localities and their own cultural properties.

\section{Materials and Methods}

Literature studies, observations, and in-depth interviews were used to identify the roles and characteristics of the community and its cultural resources in heritage areas. Basic research was conducted to investigate the operation of sustainable development at the theoretical level. Based on the theoretical review, site selection for the actual field study was carried out, and expert interviews were conducted, if necessary.

Focus group observation, discussion, and interviews were organized to gain appropriate insight into the subject, then the historical and cultural assets of the area were summarized and described through the participation and testimony of community residents. Observations were performed on community cultural properties at the site, and audio and visual data was collected by photography and voice recordings of community residents. The research outline and methodology of field research are summarized in Figure 1 below.

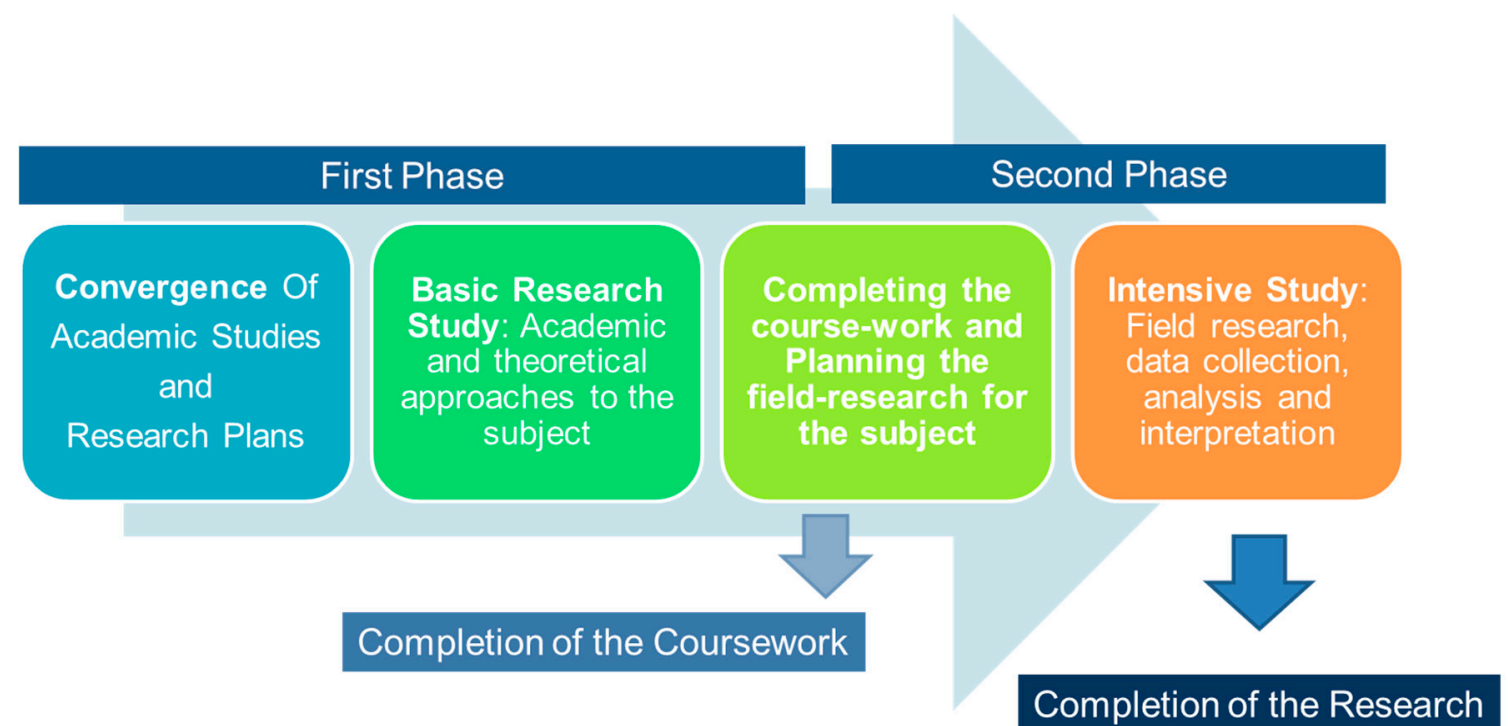

Figure 1. Outline of the research flow and methodology of the study on community cultural resources for sustainable development.

The main concepts and research directions for studying the characteristics of community culture were formed with a basis of the following framework analysis. The theoretical background for the community research from the basic survey was (A) social and cultural network perspectives, (B) urban anthropological perspectives, and (C) social and cultural representations of the community [22]. The details of the community field research frameworks are summarized in Table 1. 
Table 1. Community field research frameworks

\begin{tabular}{|c|c|}
\hline Field Research Aspects & Attributes \\
\hline $\begin{array}{l}\text { Social and Cultural } \\
\text { Network Perspective }\end{array}$ & $\begin{array}{l}\text { Responses to local and social issues based on the bonds formed by sharing and } \\
\text { collecting opinions } \\
\text { High levels of personal and collective involvement in local identity } \\
\text { Formation of channels for sharing opinions through online/offline multimedia } \\
\text { Maintenance of the sustainability of community activities } \\
\text { Active creation and intervention of indigenous knowledge and community } \\
\text { interaction }\end{array}$ \\
\hline $\begin{array}{c}\text { Urban Anthropological } \\
\text { Perspective }\end{array}$ & $\begin{array}{l}\text { High levels of human value and semantics of community formation } \\
\text { Easy community-focused access to local resources and cultural properties } \\
\text { Context of the relationship between the conditions of life in the city and community } \\
\text { formation, such as urban mobility, place-making, creation of public spaces, urban } \\
\text { policy, and governance }\end{array}$ \\
\hline $\begin{array}{l}\text { Social and Cultural } \\
\text { Representations }\end{array}$ & $\begin{array}{l}\text { Interrelationships between residents and places with unique local culture in the city } \\
\text { Interactions between non-residents and residents as social beings with diverse } \\
\text { layers and ages } \\
\text { Roles of cultural and social relations as a factor that mediates regional identities, } \\
\text { collective identities, and people's sense of belonging } \\
\text { The inherent value of local natural assets, historical and cultural assets, social } \\
\text { assets, and the specificity of utilization and reproduction methods as city assets } \\
\text { Provision of the criteria for the visualization of identity of the mix of local residents } \\
\text { and the sites } \\
\text { Provision of the rationale for combining community activities and local events as } \\
\text { catalysts for cultural mediation, social communication, and identity formation } \\
\text { A series of acts that commemorate, share, and record community memories and } \\
\text { local history }\end{array}$ \\
\hline
\end{tabular}

As mentioned, the basic direction for field research was established, and research has been conducted on local community activities and characteristics at cultural heritage sites. Some aspects of frameworks have more intangible features than others. That is, community constitutes the primary fields in which the meaning of our sustainable lives is expressed, debated, and transmitted. Obviously, sometimes cultural meaning is inherent in activities, but in some phase, it is deliberately purposeful. In the comparative case study in this paper, I try to examine this issue from the perspective of the community context, cultural properties, and community engagements.

\section{Comparative Case Study: Bukjeong Village, Korea and Honmura Area, Japan}

\subsection{Heritage and Community: Bukjeong Village in Seoul, Korea}

\subsubsection{Context}

Since Hanyang was designated the capital of Korea in 1394, the relics of Hanyang clearly connect the regional, historical, and spiritual origins of Seoul to the present. Hanyang is a symbolic old city heritage that represents the historical and cultural identity of Seoul, transformed into an urbanized megacity.

Following its construction in 1394, the Hanyang City Wall covered a total of $18.6 \mathrm{~km}$ of the city, connecting the four major gates and the four minor gates. During the Japanese colonial period and the turbulence of the Korean War, only $13 \mathrm{~km}$ of the original castle were preserved. The remains of the old city are cultural properties containing 600 years of history, with dynamic changes through urbanization, and the cultural identity of Seoul.

The formation of a castle town outside the city was the result of inhabitants losing their land in rural areas after the Japanese colonial period. Gradually, the castle town became a place where a myriad of homeless people came to settle following floods, natural disasters, and sudden social changes. A series of resident groups began to form on the hillside, under the wall, beside the railroad, beside the river, and under the bridge. The vicinity of the castle was not an existing residential area because of the steepness of the hill [23]. 
Bukjeong village is a part of this history and is located in the northern hilly area of Seoul, adjacent to the Seongbuk section of the Hanyang City Wall. The residents of Bukjeong village have a long average period of residence, and there is a high percentage of elderly people, and a high degree of community-centered utilization of local resources. Bukjeong village and residential area adjacent to the historical heritage are shown in Figure 2 below.

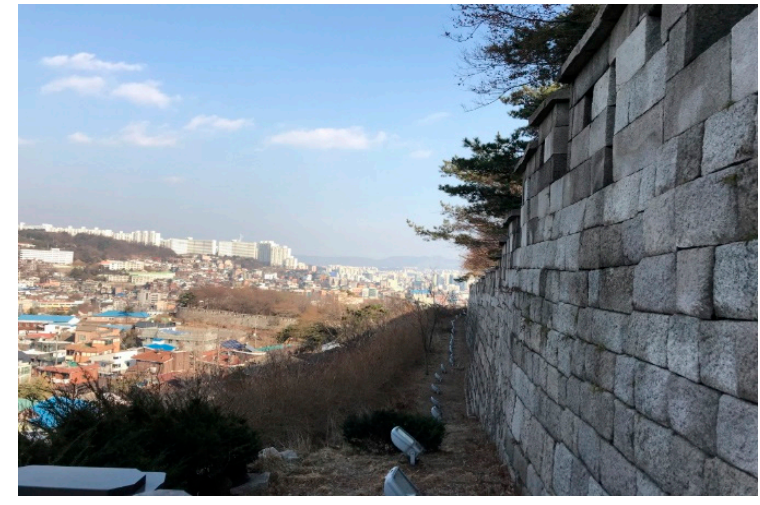

(a)

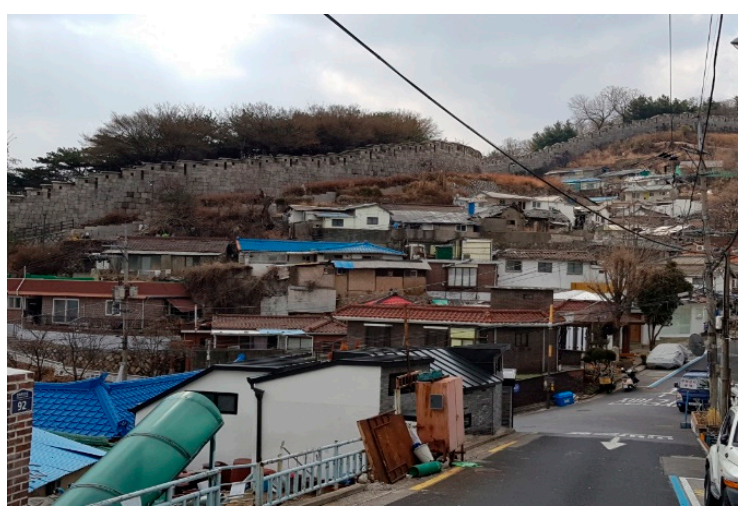

(b)

Figure 2. (a) The Hanyang City Wall and the inhabited area formed immediately adjacent to the Wall; (b) Bukjeong village at the Seongbuk section of the Hanyang City Wall.

\subsubsection{Cultural Properties}

The Hanyang City Wall is a historical site that embodies the concept of East Asian castle building and the reign of the Confucian dynasty. It is also a record of urban reconstruction and development beyond the original functional purpose of defense at the time of construction. Moreover, the city wall is the source of local community culture that formed around it. The historically formed community along with the Hanyang City Wall is a stronger fusion of cultural heritage and identity of local residents than other regions of Seoul.

Nowadays, in various discussions, there is a tendency to include the factor of human lives that directly or indirectly relate to cultural heritage. Moreover, the notion of cultural properties has expanded, ranging from the urban structure to the unique characteristics of a location, as well as to the cultural activities of the community.

Bukjeong village, located at a scenic area with a beautiful landscape, was established very close to the mountains during the Joseon Dynasty. It was a well-known place where intellectuals, writers, and poets went to escape political confusion. In the Japanese colonial period, there were many residences of famous writers and artists and villas of the wealthy in the region. Moreover, there were also historical and cultural spots around the village from which independence activists led national movements in opposition to Japanese imperialism.

Based on this cultural and historical background, the Bukjeong village communities with a unique local culture and bond were formed in the region. The community that was established along the Hanyang City Wall has recently been attracting significant attention as an intangible cultural property. It needs to be evaluated again and protected, along with the Hanyang City Wall, as an urban cultural resource. Figure 3 shows examples of program development using the cultural properties of Bukjeong village, suggesting the possibility of forming sustainable cultural properties in which the community participates. 


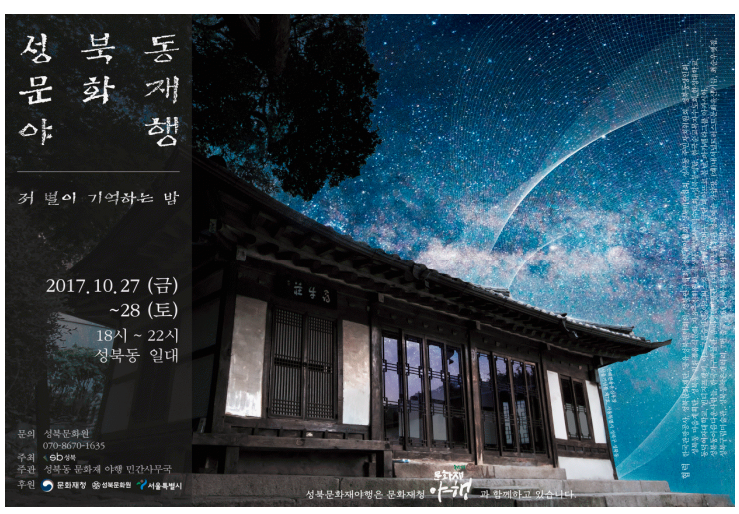

(a)

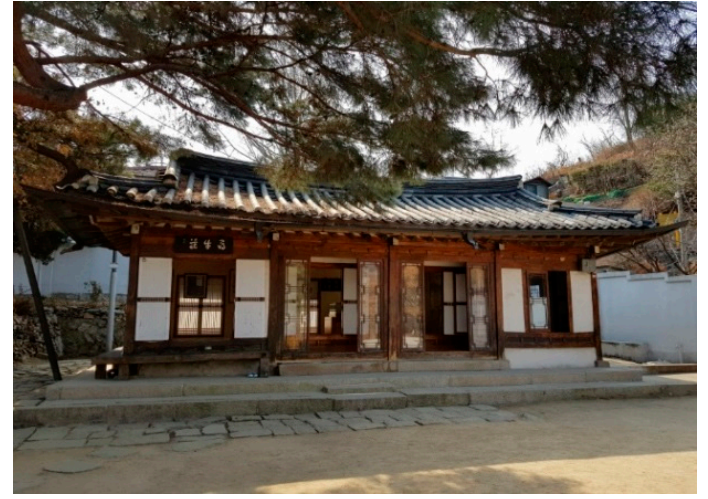

(b)

Figure 3. (a) Site-specific program poster, Hanyang City Wall night walking, utilizing historical buildings in Bukjeong village; (b) A representative cultural property in Bukjeong village, a historical house, Simujang.

\subsubsection{Community Engagements}

Seoul supports the activities of local communities for securing their own local identities, which were historically formed along the Hanyang City Wall. This support has taken several directions, such as restoring the pride of the residents living near the heritage sites, sharing heritage values, and actively preserving the heritages for future generations. In Bukjeong village, there are a variety of communities, civic groups such as residents' associations, and other social and cultural groups that actively support the cultural properties in the region.

As mentioned earlier, Bukjeong village was formed during a long average residence period, and there is a high percentage of elderly people living in this area, and a high level of community-centered utilization of local resources. In addition to these points, which are common with other communities in the region, Bukjeong village differs with the others in terms of the sustainability of community activities, public spaces, and the composition of governance.

The community is now actively involved in developing its cultural properties by creating traditional healthy food such as home-made tofu and Meju which contains fermented soybeans, and by voluntary participation in community activities such as the First Full Moon Festival and the hybrid heritage festival Wall-Moon, which re-examines the historical and cultural value of the area for visitors to the village. Figure 4 shows how the community participates in the First Full Moon Festival and shows that the village café is being used as a communication place for local residents.

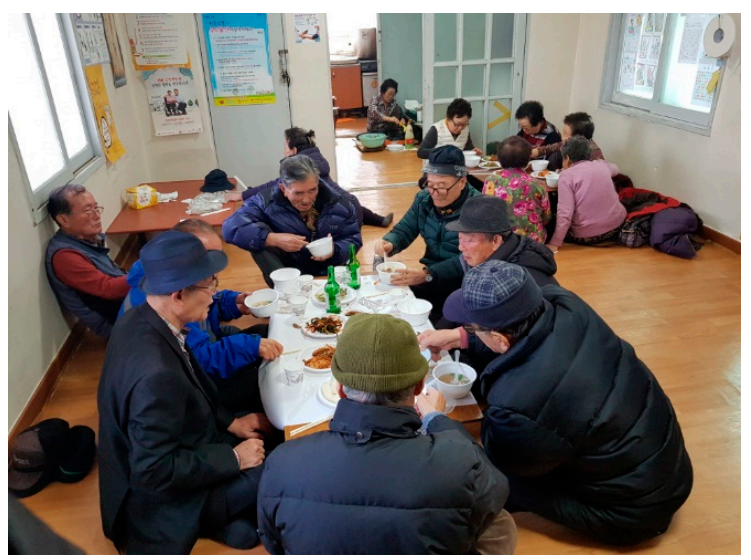

(a)

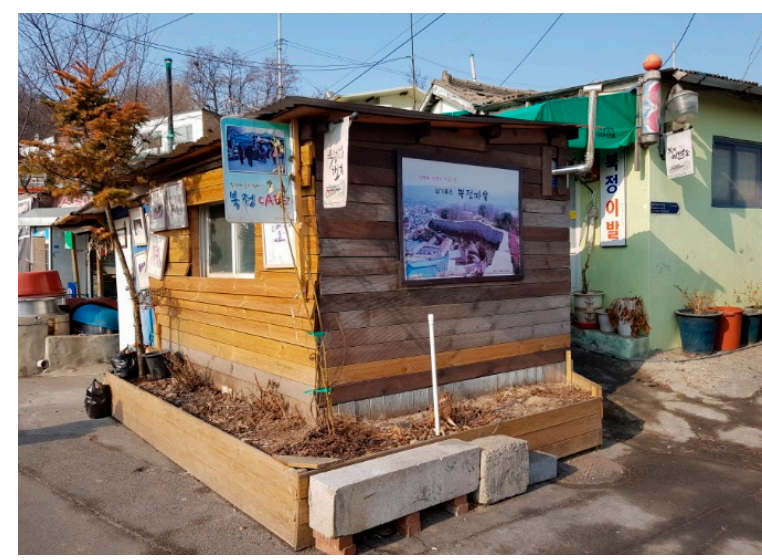

(b)

Figure 4. (a) Community lunch for seniors in Bukjeong village; (b) The Village Café, a public place for community gatherings. 


\subsection{Art Project and Community: Honmura Area in Naoshima Island, Japan}

\subsubsection{Context}

Naoshima Island is one of the representative areas that symbolize the modernization of Japan. A copper smelter of Mitsubishi, one of Japan's leading companies, was located on the island, where the industrial function was emphasized. However, the plunge in copper prices led to a decline in the area-jobs decreased and the population declined. A more serious issue was environmental problems such as polluted oceans, industrial wastes, and mountains on the island degraded by pollution. In order to overcome these problems, sustainable development efforts that combined the environment and arts began. In these efforts, Soichi Fukudake of the Benesse Group and the architect Tadao Ando, who designed and conducted a major project for sustainable development, played significant roles. On Naoshima Island, site-specific art provides a unique experience that can be found only in that local area, without disrupting nature and the inhabitants' lives.

Important cultural sites that have played a major role in transforming Naoshima into a cultural island are the Benesse House Museum and the Chi Chu Art Museum. With regard to 'living well', the Benesse Group adopted culture and arts as the main mediators for the sustainable development of nature and people. In accordance with the eco-friendly Cultural Project proposed by Fukudake on Naoshima Island, the Benesse House Museum was completed in 1992 and the Chi Chu Museum of Art was completed in 2004.

An important example of the sustainable development of local communities and cultural resources in the island is the Art Project in the Honmura region. Formed in 1600, the Honmura area is a typical Japanese country village with many houses over a 100 years old. As the population in this region declined, leaving many empty houses, sustainable regional developments were introduced in the region to overcome its problems.

\subsubsection{Cultural Properties}

The Honmura area, one of the old villages in Naoshima Island, is a place with a scattering of traditional Japanese facilities such as castles, temples, shrines, and many vacant houses due to the declining and aging population [24].

The increase in the number of vacant houses in the village gave rise to a community-based project called 'Ie Project', which involved a local resident donating his old house to the community centre. 'Ie' means 'house' in Japanese. The project committee invited an artist to stay in the empty house, so that the artist could experience and interpret the surroundings and contexts sufficiently. The artist finally created installation works that are in harmony with the environment.

The first house of the 'Ie Project (Art house Project)' was completed in 1997. It is called Kadoya, and was artistically reconstructed by contemporary media artist Miyajima Tatsuo. The project has transformed a total of seven empty houses into artistic spaces. Kadoya provided island residents with a chance to rethink their cultural resources, utilizing old abandoned houses. Figure 5 shows the art project sites in the Honmura area and Kadoya, the first art house project.

The project is a prime example of sustainable development through cultural space-making, using old resources to create new properties. Particularly noteworthy is the process by which residents express their cultural values in their own places and connect their own properties with artistic activities. In addition, visitors can search for the seven main venues in the village by using maps created by the community center, allowing them to naturally visit the Honmura area and experience its meticulous living space as well as its history, culture, and the community itself.

The area, where the elderly population was the majority, is now humming with students and young people who have come to the village to volunteer and to guide the project.

The area has achieved sustainable development through art projects without violating the original culture and space of the community. The successful approach of this area has been adopted in Inujima Island, which had the same problems. 


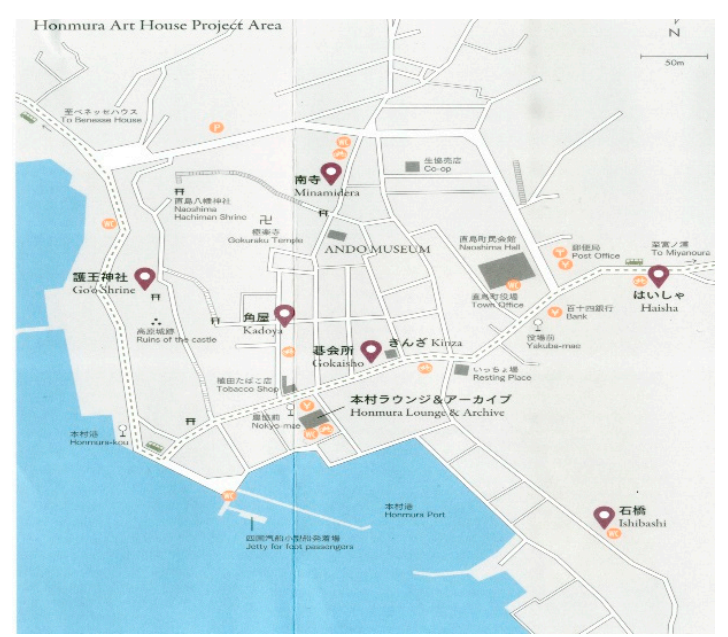

(a)

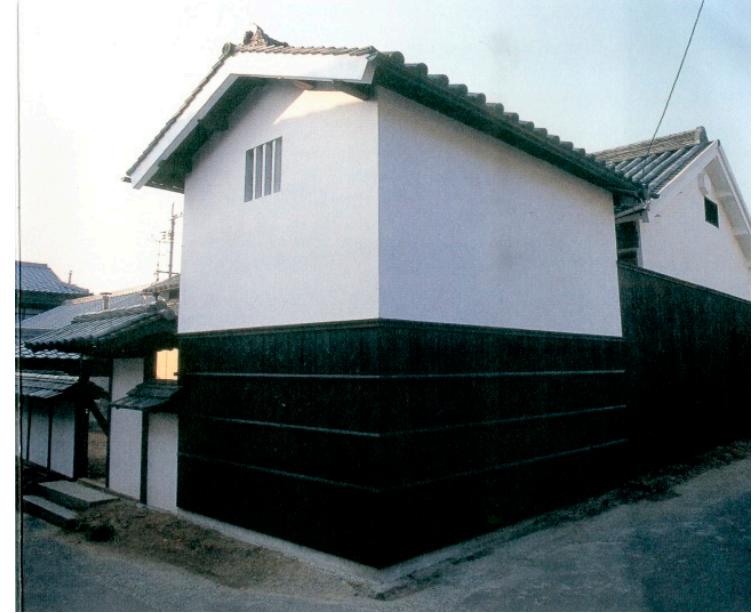

(b)

Figure 5. (a) Honmura area in Naoshima Island and the Art house project sites; (b) Kadoya in Honmura area.

\subsubsection{Community Engagements}

The main activities of the residents are centered on several platforms. The community center is a representative space that sells tour tickets and related cultural goods, in addition to providing village-related information. It also plays an important role in collecting and managing archives related to the region.

Naoshima Hall is an eco-friendly community platform that takes into consideration the wind and natural light as space elements maintaining the traditional Japanese style of house. This hall is a community space that is sometimes used by local residents as a stage for traditional cultural events such as Kabuki performances or as a space for athletic and socio-cultural activities; it is usually used as a 'life space' for the community. Figure 6 shows eco-friendly community platform, Naoshima Hall and the local shop managed by residents.

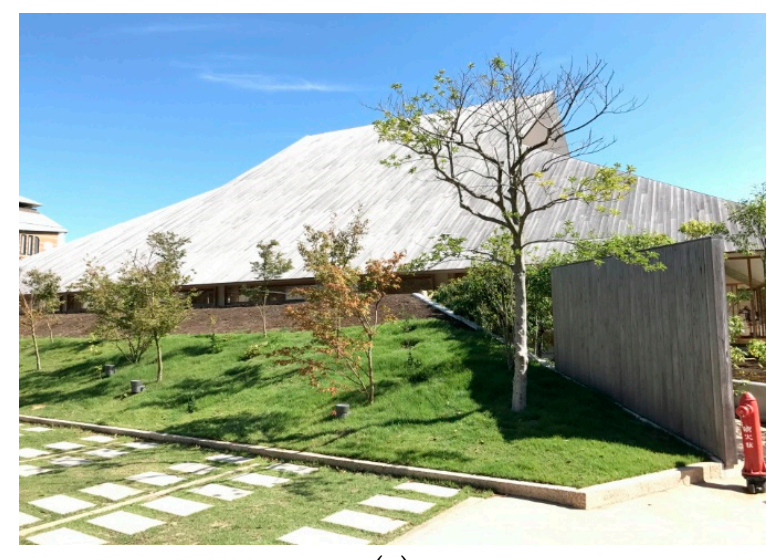

(a)

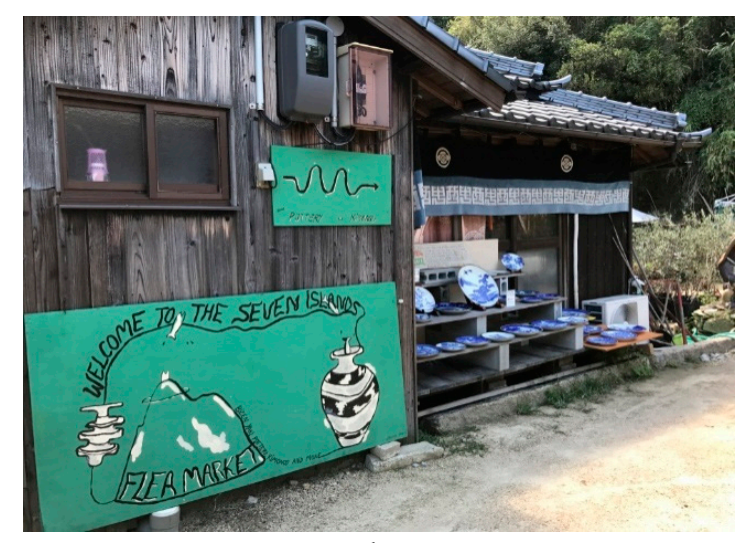

(b)

Figure 6. (a) Eco-friendly community platform, Naoshima Hall; (b) Local souvenir shops by residents.

Naoshima Island, under the leadership of Benesse Corporation, has promoted sustainable regional development by introducing culture and arts to regenerate the region. In particular, this success was made possible because the local community, populated by the elderly, made efforts to better itself. Nowadays, countless tourists visit the area and go around the village with maps. The elderly residents who occupy the actual living spaces have adapted to these changes at the community level and have restored their resilience for other changes. 
Using community cultural properties and collective governance-style art projects, sustainable development has been successfully completed in this region and there are wide socio-cultural effects. Community-based art projects have addressed sustainable development and residents' well-being and greater participation in community life. This all began with the simple desire to improve the physical, social, and economic well-being of the area, and has resulted in significant improvements in the quality of life of residents through resilience of the culture of the community.

\section{Implementation and Conclusions}

As can be seen in these cases, the use of cultural resources that emphasize the roles and responsibilities of the community in sustainable regional development have become important factors in their development. Sustainability should be actively discussed not only with economic and environmental aspects but also with cultural and social factors as well. Sustainable development strategies are responsible for the historical-cultural context and the uniqueness of a place and community. Moreover, community-based approaches to development are the most effective and sustainable ones.

Over the past few decades, statistics, indicators, and data on the cultural sector, as well as operational activities have underscored the idea that culture can be a powerful driver for development, with community-wide social, economic, and environmental impacts [25]. Similarly, cultural properties have evolved to include landscapes, industrial relics, local heritage, vernacular constructions, urban and rural settlements, and intangible elements such as temporary art performances and even ways of life [15]. The idea of sustainable development has also expanded along with the expansion of cultural properties.

Although slow at first, communities are now actively involved in developing cultural properties that are part of their own environments. Community-based cultural properties are generally focused on aspects that are perceived as familiar by the inhabitants but as unique by visitors. They are associated with a historic past and sometimes with the community's narratives that align with site-specific artworks, and therefore, these intangible elements are subsumed into the special local cultural resources.

The various representations of culture provide ways to sustain the culture into the future, and that culture is essentially different from what it was in the past. These representations include the intangible elements of culture that comprise the cultural properties which are more ephemeral than buildings and townscapes, but still are essential elements of culture. These include spoken stories, seasonal community activities, food, clothing, dance, way of life, and even memories [26].

What the above suggests that for sustainable development using cultural properties, community based cultural approaches in the heritage sites should be viewed as fundamental basis for the sustainable enablers. Figure 7 shows that mainstream criteria and vision of sustainable development maintain some features such as objects and research approaches for historic and cultural heritage sites. This paper outlines process and results of the Bukjeong case in Korea and Naoshima case in Japan for constructing the sustainable development issues that have the potential for greater coherence with cultural values and community resilience.

This study investigated possible development of cultural resources for sustainable development through field research in heritage areas. The role of the local community as a cultural enabler for sustainable development and the importance of community participation were examined in the cases of Bukjeong village in Korea and Naoshima Island in Japan. Moreover, this study also analyzed cultural heritage as a sustainable factor for urban regeneration.

To this end, this paper provides a basic discussion in this regard by recognizing the importance of the community and the restoration of community-based cultural and human values. The community plays a significant role as a sustainable element for regeneration; the restoration of local cultural values and the importance of community activities have become the main attributes of human-centered cultural urban regeneration. 


\section{Sustainable Development using Cultural Properties}

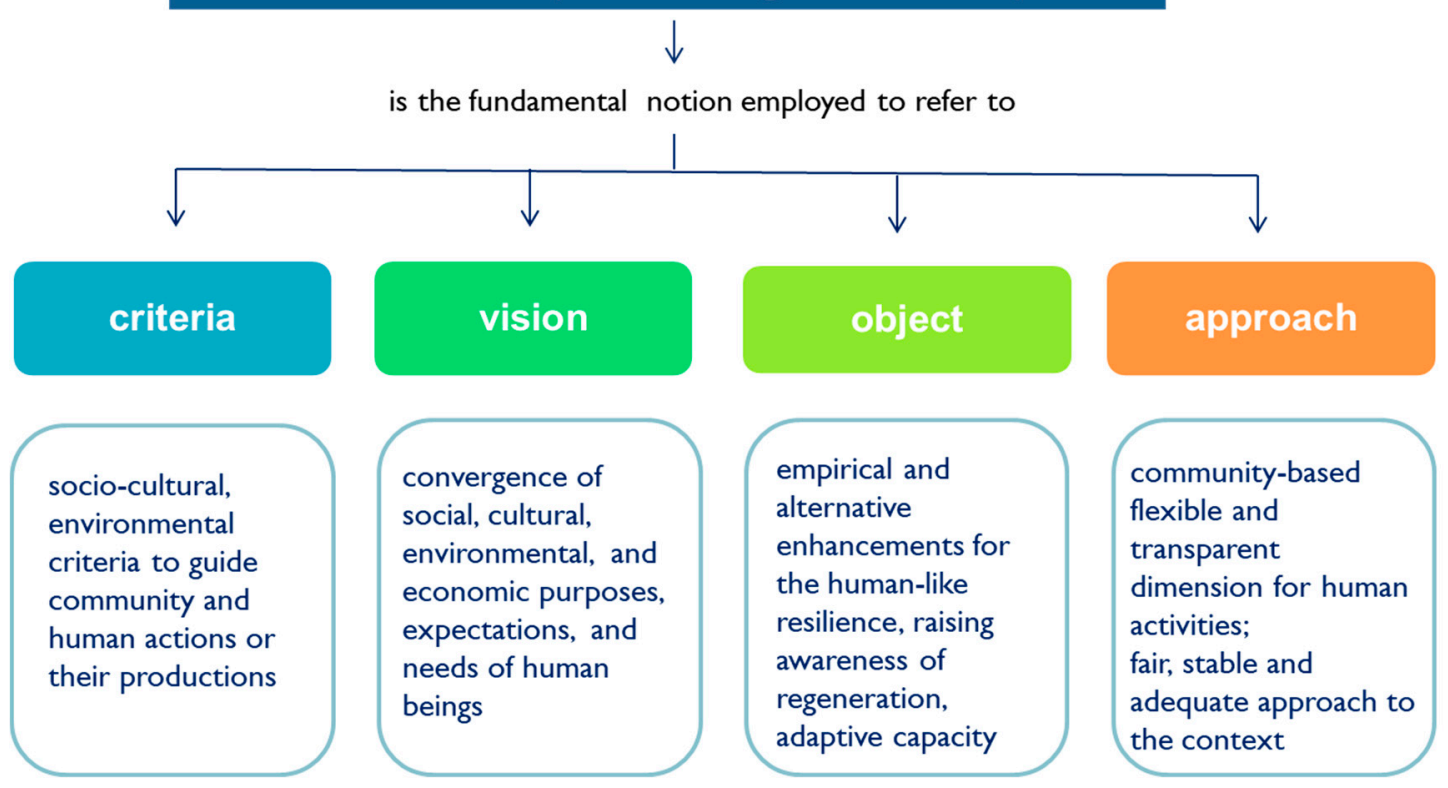

Figure 7. Process and results of the concept of sustainable development in the community.

Author Contributions: H.C. is responsible for initiating, executing, and writing the paper. J.L. provided comments and suggestions on the paper.

Funding: This research was funded by the Hankuk University of Foreign Studies Research Fund.

Conflicts of Interest: The authors declare no conflict of interest.

\section{References}

1. Seoul City Wall Research Center. Seoul City Wall; Seoul City: Seoul, Korea, 2015; pp. 90-130.

2. Seoul City Wall Museum. Seoul and Seoul City Wall. Available online: http://eng.museum.seoul.kr/eng/ about/annex/seoulCityWallMuseum.jsp (accessed on 28 November 2018).

3. Rogers, P. Conservation and implementation. In Conservation of Buildings in Developing Countries; Zetter, R., Ed.; Oxford Polytechnic: London, UK, 1982.

4. Nocca, F. The role of cultural heritage in sustainable development: Multidimensional indicators as decision-making tool. Sustainability 2017, 9, 1882. [CrossRef]

5. Brundtland, G.H. Report of the World Commission on Environment and Development: Our Common Future; United Nations: New York, NY, USA, 1987.

6. United Nations. The Future We Want: Final document of the Rio+20 Conference. In Proceedings of the Future We Want: Outcome Document of the United Nations Conference on Sustainable Development, Rio de Janeiro, Brazil, 20-22 June 2012.

7. Dempsey, N.; Bramley, G.; Power, S.; Brown, C. The social dimension of sustainable development: Defining urban social sustainability. Sustain. Dev. 2011, 19, 289-300. [CrossRef]

8. Throsby, D. Culturally sustainable development: theoretical concept or practical policy instrument? Int. J. Cult. Policy 2017, 23, 133-147. [CrossRef]

9. UN-Habitat. The State of the World's Cities 2004/2005: Globalization and Urban Culture; UNCHS: Nairobi, Kenya; Earthcam: London, UK, 2004.

10. Bulkeley, H. Urban sustainability: Learning from best practice. Environ. Plan. A 2006, 38, 1029-1044. [CrossRef]

11. UN-Habitat. Best Practices and Local Leadership. 2004. Available online: https://unhabitat.org/urbanknowledge/best-practices / (accessed on 28 November 2018).

12. United Nations. Marrakech Action Proclamation for Our Climate and Sustainable Development; United Nations: New York, NY, USA, 2016. 
13. United Nations. Trnsforming our World: The 2030 Agenda for Sustainable Development; United Nations: New York, NY, USA, 2015.

14. Evans, G. Measure for measure: Evaluating the evidence of culture's contribution to regeneration. Urban Stud. 2005, 42, 959-983. [CrossRef]

15. Powter, A.; Ross, S. Integrating environmental and cultural sustainability for heritage properties. APT Bull. 2005, 36, 5-11.

16. UNESCO. Convention for the Protection of Cultural Property in the Event of Armed Conflict with Regulations for the Execution of the Convention 1954; UNESCO: Hague, The Netherlands, 1954; Available online: http:/ / portal. unesco.org/en/ev.php-URL_ID=13637\&URL_DO=DO_TOPIC\&URL_SECTION=201.html (accessed on 28 December 2018).

17. UNESCO. Convention Concerning the Protection of the World Cultural and Natural Heritage; The General Conference of UNESCO: Paris, France, 1972; Available online: https:/ / whc.unesco.org/en/conventiontext/ (accessed on 28 December 2018).

18. Poulios, J. The Past in the Present; Ubiquity Press: London, UK, 2014.

19. Roberts, P.; Sykes, H. Urban Regeneration; Sage Publications Ltd.: London, UK, 2006.

20. Evans, G.; Shaw, P. The Contribution of Culture to Regeneration in the UK: A Report to the DCMS; London Metropolitan University: London, UK, 2004.

21. Burns, D.; Hambleton, R.; Hoggett, P. The Politics of Decentralization: Revitalising Local Democracy; Macmillan: Hampshire, UK, 1994.

22. Jaffe, R.; de Koning, A. Introducing Urban Anthropology; Routledge: New York, NY, USA, 2016.

23. On Space; Seoul Research Institute; Doga Architecture. A Comprehensive Plan for the Preservation and Management of Castle Town around Hanyang; Seoul City: Seoul, Korea, 2014.

24. Fukutake, S.; Ando, T.; Lee, U.; Tatsuo, M.; Hiroshi, S.; Ohtake, S. Naoshima Setochi Art no Rakuen; Shinchosha Publishing: Tokyo, Japan, 2013.

25. UNESCO. Culture: A Driver and an Enabler of Sustainable Development; Thematic Think Piece; UNESCO: London, UK, 2012; Available online: http://www.unesco.org/new/fileadmin/MULTIMEDIA/HQ/ post2015/pdf/Think_Piece_Culture.pdf (accessed on 28 December 2018).

26. Bennett, D.; Reid, A.; Petocz, P. Creative workers' views on cultural heritage and sustainability. J. Aesthet. Cult. 2014, 6, 2-25. [CrossRef] 